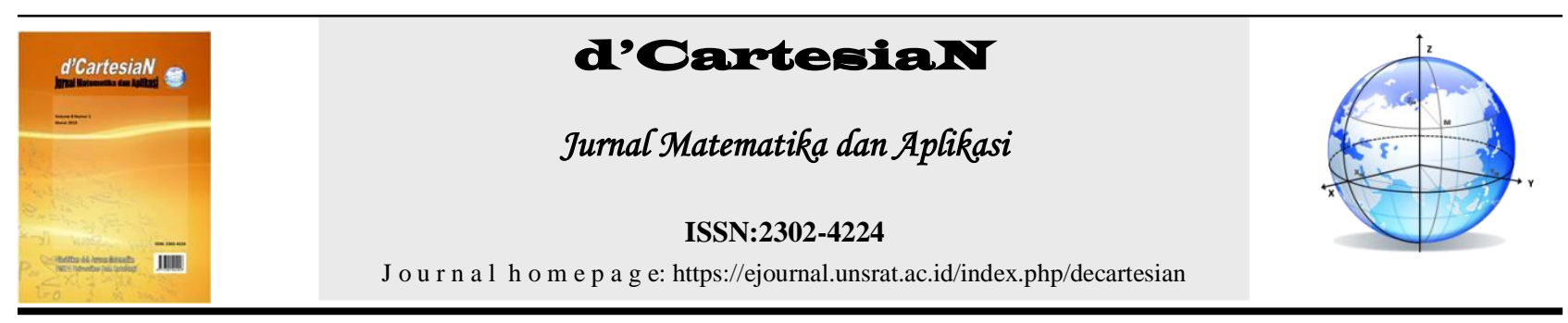

\title{
Optimasi Pengaturan Lampu Lalu Lintas dengan menggunakan Metode Webster (Studi Kasus Persimpangan Jalan Babe Palar)
}

\author{
Indah Poernamasari ${ }^{1}$, Rinancy Tumilaar ${ }^{1}$, Chriestie E.J.C. Montolalu ${ }^{1^{*}}$ \\ ${ }^{1}$ Jurusan Matematika-Fakultas Matematika dan Ilmu Pengetahuan Alam-Universitas Sam Ratulangi Manado, Indonesia \\ ${ }^{*}$ Corressponding author : chriestelly@unsrat.ac.id
}

\begin{abstract}
A B S T R A K
Permasalahan pada lalu lintas disebabkan karena bertambahnya jumlah kendaraan yang beroperasi setiap harinya sehingga menyebabkan kemacetan parah dibeberapa titik, terutama pada persimpangan jalan yang memiliki lampu lalu lintas dengan nyala lampu merah yang lama dan nyala lampu hijau yang sangat singkat. Permasalahan lampu lalu lintas dapat diselesaikan dengan teori graf. Arus direpresentasikan sebagai titik dan arus yang kompatibel direpresentasikan oleh sisi. Pengoptimalan lampu lalu lintas ditentukan menggunakan metode webster. Dari penelitian yang telah dilakukan diperoleh 3 fase untuk menghitung nyala lampu pada persimpangan jalan Babe Palar dengan waktu siklus optimum yang dihasilkan sebesar 137 detik dan penambahan waktu nyala lampu hijau pada ruas jalan yang memiliki tingkat volume lalu lintas yang tinggi. Sehingga, penghitungan dengan metode webster dikatakan efektif.
\end{abstract}

\section{INFO ARTIKEL}

Diterima : 16 Maret 2019

Diterima setelah revisi : 23 Maret 2019

Tersedia online : 31 Maret 2019

\section{Kata Kunci:}

Pengaturan Lampu Lalu Lintas

Graf Berarah

Graf Berbobot

Metode Webster

\section{PENDAHULUAN}

Dijumpai di kota-kota besar di Indonesia, beberapa faktor penyebab kemacetan adalah kurangnya disiplin pengguna jalan dan volume kendaraan yang semakin bertambah. Permasalahan ini dapat diselesaikan salah satunya dengan pengaturan lampu lalu lintas [11].

Manado merupakan kota terbesar kedua di pulau Sulawesi setelah Makassar [17], oleh karena itu Kota Manado mempunyai banyak permasalahan salah satunya permasalahan lalu lintas, hal ini disebabkan karena bertambahnya jumlah kendaraan yang beroperasi setiap harinya sehingga menyebabkan terjadinya kepadatan lalu lintas yang cukup tinggi di sejumlah titik tertentu, khususnya di titik yang daerahnya memiliki persimpangan jalan. Hal itu menyebabkan terjadinya penumpukan kendaraan sehingga kinerja pada persimpangan jalan tersebut menjadi kurang optimal.

Menurut Departemen Perhubungan Direktorat Jenderal Perhubungan Darat (1996), persimpangan adalah simpul pada jaringan jalan dimana jalan-jalan bertemu dan lintasan kendaraan berpotongan lalu lintas pada masing-masing kaki persimpangan bergerak secara bersama-sama dengan lalu lintas lainnya. Persimpangan-persimpangan merupakan faktor-faktor yang paling penting dalam menentukan kapasitas dan waktu perjalanan pada suatu jaringan jalan khususnya di daerah-daerah perkotaan [6].
Menurut UU No. 22 Tahun 2009 tentang Lalu Lintas dan Angkutan Jalan, lampu lalu lintas yang tersedia di persimpangan jalan mempunyai beberapa tujuan antara lain menghindari hambatan karena adanya perbedaan arus jalan bagi pergerakan kendaraan, memfasilitasi pejalan kaki agar dapat menyebrang dengan aman dan mengurangi tingkat kecelakaan yang diakibatkan oleh tabrakan karena perbedaan arus jalan. Karena fungsinya yang begitu penting maka lampu lalu lintas harus dapat dikendalikan atau dikontrol dengan semudah mungkin demi memperlancar arus lalu lintas di suatu persimpangan jalan.

Sebagian besar pengaturan lampu lalu lintas (traffic light) pada saat ini masih kurang optimal karena pada persimpangan jalan banyak ditemui lampu lalu lintas (traffic light) dengan durasi lampu hijau yang singkat dan lampu merah yang lama. Hal ini menyebabkan terjadinya peningkatan antrian kendaraan pada persimpangan tersebut [11].

Menurut beberapa penelitian sebelumnya [10] dan [1], penyelesaian masalah lampu lalu lintas dapat ditinjau dalam perspektif graf, yaitu dengan merepresentasikan persimpangan dalam bentuk graf. Titik pada graf menunjukkan arah perjalanan yang diperbolehkan dari jalan X menuju Y, sedangkan sisi graf menunjukkan arah perjalanan yang boleh dilakukan secara bersamaan. Selanjutnya menyelesaikannya 
dengan metode Webster. Penyelesaian ini bertujuan untuk mengetahui pengaturan lampu lalu lintas.

Metode ini digunakan [10] untuk mengoptimalkan lalu lintas di Simpang Empat Jalan Usman Salengke - K. H. Wahid Hasyim - Poros Malino Makassar, [1] pada Simpang Empat Semplak Bogor dan [2] menggunakan Metode serupa pada persimpangan Iskandar Muda kota Medan.

Dalam penelitian ini menggunakan dua data yakni data sekunder yang diambil di dinas perhubungan Kota Manado dan data primer yakni tingkat volume lalu lintas per ruas jalan yang dicatat selama satu jam pada pagi hari jam 07.30 - 08.30 dengan asumsi banyaknya pekerja dan pelajar yang berangkat, pada siang hari 12.00 - 13.00 dengan asumsi banyaknya pelajar yang pulang dan pada sore hari jam 16.30 - 17.30 dengan asumsi banyaknya pekerja yang pulang disertai dengan aktifitas lain, kemudiadata tersebut diolah dengan menggunakan metode Webster dan menghasilkan waktu siklus optimal.

\section{Lalu Lintas}

Lalu lintas adalah suatu keadaan dengan pengaturan menggunakan lampu lalu lintas yang terpasang pada persimpangan dengan tujuan untuk mengatur arus lalu lintas. Pengaturan arus lalu lintas pada persimpangan pada dasarnya dimaksudkan untuk bagaimana pergerakan kendaraan pada masing-masing kelompok pergerakan kendaraan dapat bergerak secara bergantian sehingga tidak saling mengganggu antar arus yang ada.

Ada berbagai jenis kendali dengan menggunakan lampu lalu lintas dimana pertimbangan ini sangat bergantung pada situasi dan kondisi persimpangan seperti volume, geometri simpang, dan sebagainya [10].

\subsection{Persimpangan}

Simpang adalah bagian yang sulit dihindarkan dalam jaringan jalan, karena persimpangan jalan merupakan tempat bertemu dan berganti arah arus lalu lintas dari dua jalan atau lebih. Ketika berkendara di dalam kota orang dapat melihat bahwa kebanyakan jalan di daerah perkotaan biasanya memiliki persimpangan, dimana pengemudi dapat memutuskan untuk jalan terus, berbelok atau pindah jalan [6].

Persimpangan jalan dapat diartikan sebagai dua jalur atau lebih ruas jalan yang berpotongan, dan termasuk di dalamnya fasilitas jalur jalan dan tepi jalan. Sedangkan setiap jalan yang memancar dan merupakan bagian dari persimpangan tersebut disebut lengan persimpangan. Persimpangan jalan merupakan suatu hal yang penting untuk di analisa karena sangat berpengaruh terhadap aliran dan keselamatan berlalu lintas.

\subsection{Pengendalian Persimpangan}

Terdapat paling tidak enam cara utama untuk mengendalikan lalu-lintas di persimpangan, bergantung pada jenis persimpangan dan volume lalu lintas pada tiap aliran kendaraan, berdasarkan urutan tingkat pengendalian, dari kecil ke tinggi, di persimpangan, keenamnya adalah tanpa kendali, kanalisasi, rambu pengendali kecepatan atau rambu berhenti, bundaran dan lampu lalu lintas [6]).

Arus Lalu Lintas (Q) untuk setiap gerakan dikonversi dari kendaraan per jam menjadi satuan mobil penumpang (smp) per jam dengan menggunakan ekivalen kendaraan penumpang (emp) untuk masing masing pendekat terlindung terlawan [4].

Tabel 1. Konversi Kendaraan Terhadap Stuan Mobil Penumpang

\begin{tabular}{|c|c|c|}
\hline \multirow{2}{*}{ Jenis Kendaraan } & \multicolumn{2}{|c|}{ (emp) untuk tipe pendekat } \\
\cline { 2 - 3 } & Terlindung & Terlawan \\
\hline Kendaraan Berat (HV) & 1,3 & 1,3 \\
\hline Kendaraan Ringan (LV) & 1,0 & 1,0 \\
\hline Sepeda Motor (MC) & 0,2 & 0,4 \\
\hline
\end{tabular}

\subsection{Beberapa Istilah Lalu Lintas}

Pada perencanaan lalu lintas, dikenal beberapa istilah :

1. Waktu Siklus (cycle time) : waktu satu periode lampu lalu lintas, misalnya pada saat suatu arus diruas jalan A mulai hijau, hingga pada ruas jalan tersebut mulai hijau lagi.

2. Fase : suatu tahapan sinyal dalam waktu satu atau lebih pergerakan lalu lintas mendapatkan kesempatan bergerak.

3. suatu rangkaian dari kondisi yang diberlakukan untuk suatu arus atau beberapa arus yang mendapatkan indentifikasi lampu lalu lintas yang sama.

4. Bentuk Alih Gerak (manuver) : dari sifat dan tujuan gerakan di daerah persimpangan, dikenal beberapa bentuk alih gerak (manuver) antara lain, diverging (memisah), merging (menggabung), crossing (memotong), dan weaving (menyilang) [3].

\section{Teori Graf}

\subsection{Sejarah}

Jembatan Königsberg adalah masalah yang pertama kali menggunakan Graf pada tahun 1739, di kota Königsberg terdapat sungai pregal yang mengalir mengitari pulau kneiphof lalu bercabang menjadi dua buah anak pulau yang terlihat pada Gambar 1 . Permasalahannya ialah menemukan perjalanan atau rute dari suatu kota melalui ketujuh jembatan masingmasing tepat satu kali, kemudian kembali lagi ke tempat awal. Pulau tersebut tidak bisa dicapai oleh rute manapun selain melalui jembatan-jembatan tersebut [7]. 


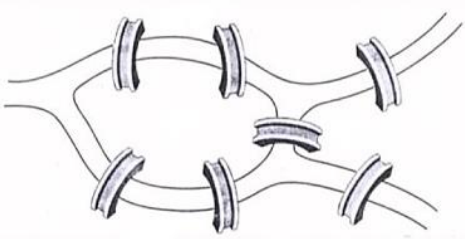

Gambar 1. Jembatan-jembatan di Königsberg

\subsubsection{Definisi}

Sebuah graf $G=(V, E)$ terdiri atas $V$, sebuah himpunan titik-titik (vertices) yang tidak kosong dan $E$, sebuah himpunan garis-garis (edges). Setiap garis memiliki antara satu atau dua titik-titik yang terhubung dengannya, yang disebut titik-titik ujungnya (endpoints) [12].

\subsubsection{Jenis-Jenis Graf}

Jenis Graf berdasarkan orientasi arah pada sisi, dapat dibedakan menjadi :

\section{Graf Berarah}

Graf yang setiap sisinya diberikan orientasi arah disebut sebagai graf berarah. Sisi berarah dapat disebut sebagai busur (arc). Pada graf berarah, $(u, v)$ dan $(v, u)$ menyatakan dua buah busur yang berbeda, dengan kata lain $(u, v) \neq(v, u)$. Untuk busur $(u, v)$, simpul $u$ dinamakan simpul asal (initial vertex) dan simpul $v$ dinamakan simpul terminal (terminal vertex) [8].

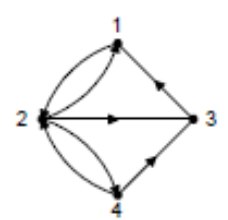

(a) $G_{1}$

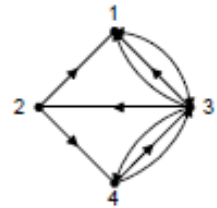

(b) $G_{2}$
Gambar 2. (a) Graf Berarah, (b) Graf ganda Berarah

2. Graf Tidak Berarah

Graf yang sisinya tidak mempunyai orientasi arah disebut graf tak-berarah. Pada graf tak-berubah, urutan pasangan simpul yang dihubungkan oleh sisi tidak diperhatikan. Jadi, $(u, v)=(v, u)$ adalah sisi yang sama [8].
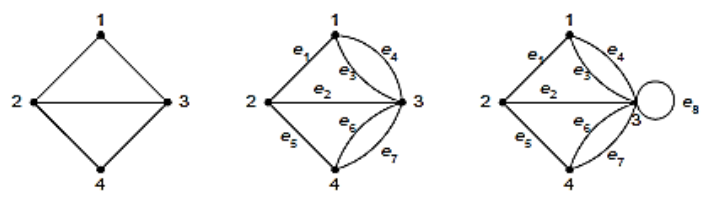

Gambar 3. Graf tak berarah

Menurut [9] Graf dapat dikelompokkan menjadi beberapa kategori (jenis) bergantung pada sudut pandang pengelompokkannya :

1. Graf Sederhana

Graf yang tidak mengandung gelang maupun sisi-ganda dinamakan graf sederhana.

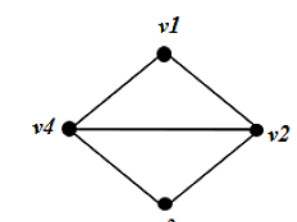

Gambar 4. ${ }^{v}$ Graf Sedehana

2. Graf Tak Sederhana

Yaitu graf yang mengandung sisi ganda atau gelang dinamakan graf tak sederhana. Ada dua macam graf tak sederhana, yaitu :

a. Graf Ganda

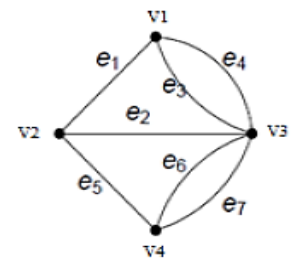

Gambar 5. Graf Ganda

b. Graf Semu

Graf Semu adalah Graf yang mengandung gelang dan lebih umum daripada Graf ganda, karena sisi graf semu lebih umum daripada graf ganda.

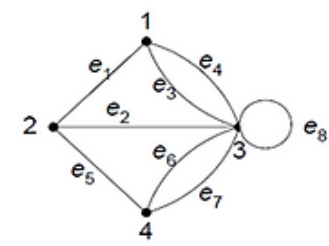

Gambar 6. Graf Semu

\section{Graf Berbobot}

Graf Berbobot adalah graf yang pada setiap sisinya diberikan harga (Bobot), bobot pada setiap sisi dapat berbeda beda bergantung pada masalah yang dimodelkan dengan graf. Bobot dapat menyatakan jarak antara dua buah kota, biaya perjalanan antara dua buah kota, waktu tempuh pesan (message) dari sebuah simpul komunikasi ke simpul komunikasi lain [8].

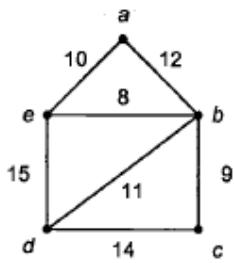

Gambar 7. Graf Berbobot

4. Graf Ganda Berarah Berbobot

Graf Ganda Berarah Berbobot adalah gabungan dari Graf Ganda, Graf Berarah dan Graf Berbobot [16]. 


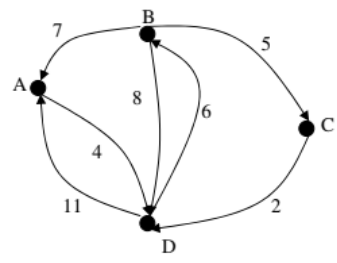

Gambar 8. Graf Ganda Berarah Berbobot

\subsection{Hubungan Graf Pada Arus Kompabilitas}

Kompabilitas diartikan adalah sejauh mana suatu kinerja dianggap kompatibel (sesuai) dengan sistem yang mempunyai nilai, pengalaman dan kebutuhan tanpa mengubah apapun dari sistem konsumen yang sudah ada.

Arus lalu lintas dapat disebut kompatibel jika kedua arus tersebut tidak akan menghasilkan perselisihan yang disebabkan oleh kendaraan. [5].

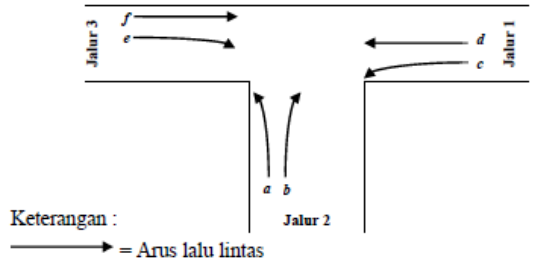

Gambar 9. Contoh Skema Persimpangan arus Kompabilitas

Pada gambar skema diketahui arus lalu lintas yang kompatibel. Beberapa contoh arus lalu lintas yang kompatibel yaitu arus kendaraan $a$ kompatibel dengan arus kendaraan $b$ dan $f$, sedangkan arus $b$ kompatibel dengan arus kendaraan $a, c, d$ dan $f$. Arus lalu lintas dari gambar tersebut yang disalin dalam graf yang simpulnya mewakili arus lalu lintas dan sisi mewakili pasangan simpul yang arusnya kompatibel ditunjukkan pada gambar sebagai berikut : [2].

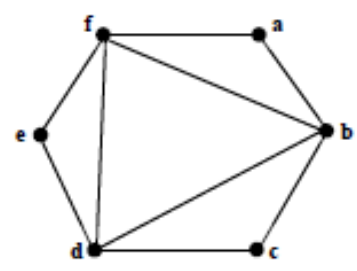

Gambar 1o. Graf Kompatibel dari Skema

\subsection{Metode Webster}

F. V. Webster mengembangkan persamaan klasik untuk menghitung penundaan rata rata perkendaraan ketika mendekati persimpangan dan juga menurunkan sebuah persamaan untuk memperoleh waktu siklus optimum yang menghasilkan penundaan kendaraan minimum. Penundaan kendaraan terjadi karena jumlah kendaraan yang masuk ke dalam sebuah persimpangan lebih besar dibandingkan dengan jumlah kendaraan yang keluar dari persimpangan tersebut [13].

Kelebihan dari metode Webster adalah penggunaan dari metode ini sangat mudah dalam pengerjaannya, selain itu pada metode ini untuk jalan dengan volume kendaraan yang tinggi akan terjadi penambahan lama waktu lampu hijau.

\subsection{Arus Jenuh}

Arus jenuh adalah banyaknya keberangkatan kendaraan pada antrian saat kendaraan berada di laju konstan, yakni setelah melakukan percepatan, sampai kendaraan melakukan perlambatan selama periode hijau dan kuning. Arus jenuh biasanya dinyatakan dalam kendaraan per jam waktu hijau [14].

Tabel 2. Arus Jenuh pada Persimpangan untuk lebar pendekat $<5,5 \mathrm{~m}$

\begin{tabular}{|c|c|c|c|c|c|c|}
\hline $\begin{array}{c}\text { Lebar Jalan } \\
(\mathrm{m})\end{array}$ & 3 & 3.5 & 4 & 4,5 & 5 & 5,5 \\
\hline $\begin{array}{c}\text { Arus Jenuh } \\
(\mathrm{smp} / \text { jam })\end{array}$ & 1.850 & 1.875 & 1.975 & 2.175 & 2.550 & 2.900 \\
\hline
\end{tabular}

Jika lebar jalan melebihi nilai yang ditetapkan, maka arus jenuh $(s)=$ Lebar Jalan $\times 525(\mathrm{smp} /$ jam $)$, satuan mobil penumpang ( $\mathrm{smp}$ ) adalah satuan kendaraan di dalam arus lalu lintas yang disetarakan dengan kendaraan ringan atau mobil penumpang. Besaran smp dipengaruhi oleh tipe atau jenis kendaraan, dimensi kendaraan, dan kemampuan olah gerak.

\subsection{Waktu Hilang $(L)$}

Faktor yang di diperlukan untuk menghitung siklus waktu maksimum adalah waktu hilang $(L)$, yaitu lama waktu satu siklus penuh pada saat tidak ada kendaraan. Hal ini dilakukan tidak hanya waktu merah dan waktu merah/merah/kuning tetapi juga sebagai waktu persiapan jalan (Starting-Up) dan persiapan berhenti (Tailing-Off) yang terjadi pada saat perubahan warna lampu. Waktu yang tebuang dihitung dengan rumus :

Ket :

$$
L=2 n+R
$$

$n=$ Banyaknya fase

$R=$ Waktu hilang yang diakibatkan antrian (waktu kuning)

\subsection{Waktu Siklus Optimum}

Webster memberikan rumus untuk menghitung waktu siklus Optimum $\left(C_{0}\right)$ adalah [15].

Keterangan :

$$
C_{0}=\frac{1,5 \times L+5}{1-Y}
$$

$C_{0}=$ Waktu siklus (detik)

$L \quad=$ Waktu hilang total per siklus

$Y=$ Jumlah $y$ maksimum untuk semua fase

Dan untuk penghitungan nyala lampu hijau efektif pada setiap persimpangan, waktu hijau efektif yakni ketika kendaraan bergerak melintas selama periode nyala lampu hijau.

Keterangan :

$$
g=\frac{y\left(C_{0}-L\right)}{Y}
$$

$g$ = waktu hijau efektif

$y=$ tingkat arus lalu lintas tiap persimpangan

$C_{0}=$ waktu siklus

$L=$ waktu hilang total

$Y=$ jumlah $y$ maksimum untuk seluruh fase 


\section{METODE PENELITIAN}

\subsection{Waktu dan Tempat Penelitian}

Penelitian ini dilaksanakan selama bulan Oktober 2018 sampai Februari 2019. Sumber data yang diambil adalah data sekunder yang diambil di Dinas Perhubungan Kota Manado dan data Primer yang di ambil secara langsung di lapangan, pengolahan data dilakukan di Jurusan Matematika Fakultas Matematika dan Ilmu Pengetahuan Alam Universitas Sam Ratulangi Manado.

\subsection{Pengumpulan Data}

Sumber pengumpulan data yang digunakan dalam penelitian ini adalah data sekunder yang diperoleh melalui Instansi atau Lembaga yang mempunyai data yang lebih relevan yaitu Dinas Perhubungan Kota Manado, data primer yang diperoleh langsung di tempat penelitian.

\subsection{Analisi Data}

Langkah-langkah penelitiannya sebagai berikut :

1. Pengambilan data dilakukan secara sekunder dan primer data sekunder diambil di Dinas Perhubungan Kota Manado yaitu data lama waktu nyala lampu merah, kuning dan hijau untuk satu kali putaran sedangkan untuk data primer diambil secara langsung di tempat penelitian yaitu di persimpangan jalan babe palar data yang diambil yaitu volume lalu lintas yang dicatat selama 1 jam, data primer diambil pada hari minggu 10 senin dimana arus puncak terjadi.

2. Menggambar persimpangan jalan babe palar yang disertai dengan arus-arusnya.

3. Membuat arus-arus yang kompatibel dan tidak kompatibel kemudian arus kompatibel tersebut disalin ke dalam bentuk graf.

4. Menyederhanakn graf kompatibel.

5. mengubah graf kompatibel yang telah disederhanakan ke dalam bentuk graf ganda berarah berbobot dengan Asumsi :

Lebar Jalan :

a. Jalan dibawah $3 \mathrm{~m}$ diberi nilai 4

b. Antara 3 sampai $4 \mathrm{~m}$ diberi nilai 3

c. Lebih dari 4 sampai $5 \mathrm{~m}$ diberi nilai 2

d. $>5 \mathrm{~m}$ diberi nilai 1

Volume Kendaraan :

a. Diatas 2.00o Kend/Jam, diberi nilai 5

b. $1.500-1.999 \mathrm{Kend} / J a m$, diberi nilai 4

c. $1.000-1.499 \mathrm{Kend} / J a m$, diberi nilai 3

d. $500-999 \mathrm{Kend} / \mathrm{Jam}$, diberi nilai 2

e. $\quad$ - $499 \mathrm{Kend} / J a m$, diberi nilai 1

Pengasumsian pada pembobotan ini telah digunakan pada penelitian sebelumnya yakni oleh (Cahyani, 2018).

6. Mengoptimalkan pengaturan waktu lampu lalu lintas dengan menggunakan metode Webster.

\section{HASIL DAN PEMBAHASAN}

\subsection{Data Geometri}

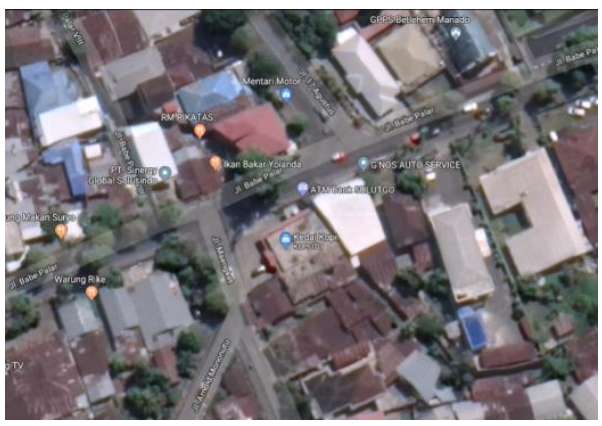

Gambar 11. Peta Persimpangan Jalan Babe Palar

Tabel 3. Data Sekunder Waktu nyala Lampu

\begin{tabular}{|l|c|c|c|}
\hline \multicolumn{1}{|c|}{ Ruas Jalan } & $\begin{array}{c}\text { Merah } \\
\text { (detik) }\end{array}$ & $\begin{array}{c}\text { Kuning } \\
\text { (detik) }\end{array}$ & $\begin{array}{c}\text { Hijau } \\
\text { (detik) }\end{array}$ \\
\hline JL. 17 Agustus & 116 & 5 & 30 \\
\hline $\begin{array}{l}\text { JL. Babe Palar } \\
\text { (Timur) }\end{array}$ & 96 & 5 & 70 \\
\hline $\begin{array}{l}\text { JL. Maengket } \\
\text { JL. Babe Palar }\end{array}$ & 96 & 5 & 70 \\
\hline \begin{tabular}{l} 
(Barat) \\
\hline
\end{tabular}
\end{tabular}

1. Untuk Jl. 17 Agustus memiliki 2 Jalur yakni jalur masuk dan keluar yang masing-masing berukuran $6 \mathrm{~m}$.

2. Pada Jl. Babe Palar (Timur) memiliki lebar jalur masuk dan keluar masing-masing sebesar $4 \mathrm{~m}$.

3. Pada Jl. Maengket memiliki lebar jalur masuk dan keluar masing-masing sebesar 4,5 m.

4. Dan pada Jl. Babe Palar (Barat) memiliki lebar yang sama dengan JL. Babe Palar (Timur) yakni jalan masuk dan keluar masing-masing sebesar $4 \mathrm{~m}$.

\subsection{Volume Lalu Lintas}

Untuk data Volume Lalu lintas dilakukan dengan cara pengambilan langsung di tempat penelitian yakni di Persimpangan Jalan Babe Palar, pengambilan data dilakukan selama dua hari yakni pada hari Minggu, 10 Februari 2019 yang mewakili hari libur dan hari Senin 18 Februari 2019 yang mewakili hari kerja efektif dari kedua hari tersebut diperoleh arus puncak yakni pada hari Senin 18 Februari 2019 jam 07.30 - 08.30 yang menjadi Volume Lalu Lintas untuk penelitian.

\subsection{Pengolahan Data}

Sistem Arus Lalu Lintas persimpangan jalan Babe Palar akan diubah ke dalam bentuk graf dengan simpul (vertex) sebagai arus dan garis (edge) sebagai 
pasangan arus yang kompatibel atau pasangan arus yang dapat berjalan secara bersamaan maksudnya arus yang dapat berjalan bersama dengan aman tanpa adanya konflik yang mungkin terjadi.

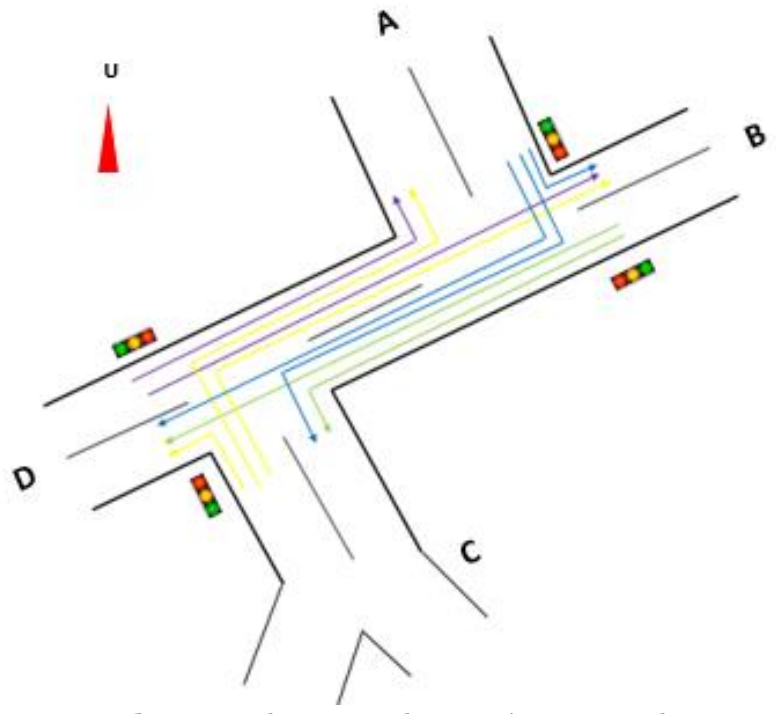

Gambar 12. Skema Real Persmipangan Jalan

Dari skema real pada persimpangan yang telah dibuat terdapat pengaturan arus yang dilarang untuk berbelok langsung ke arah kanan yakni pada arus jalan B menuju ke arah jalan A dan pada arus jalan D menuju ke arah jalan $\mathrm{C}$.

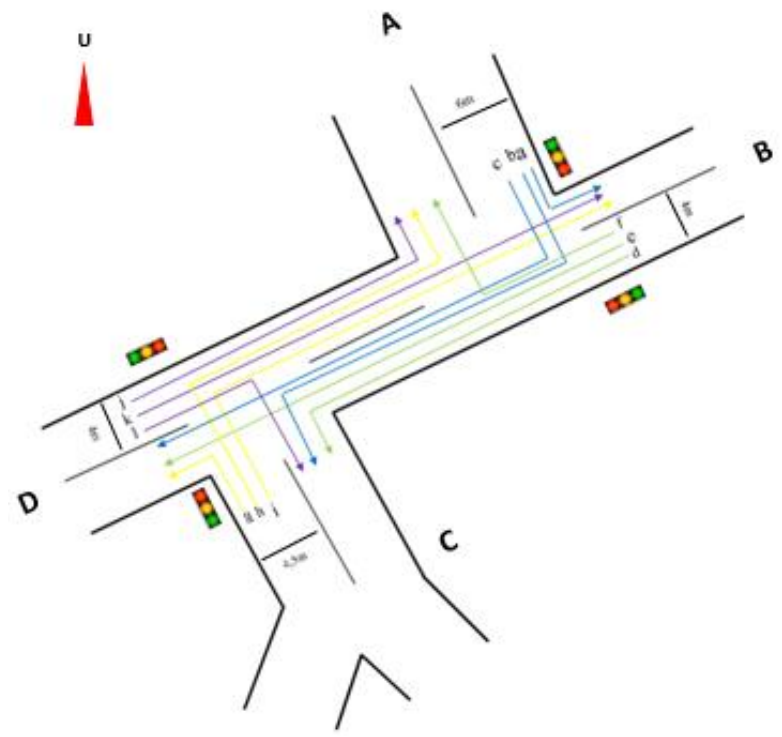

Gambar 13. Skema Asumsi Persimpangan Jalan

Kemudian pada penelitian ini pada arus yang sebelumnya terdapat pengaturan dilarang untuk berbelok langsung ke arah kanan diasumsikan untuk bisa berbelok langsung ke arah kanan seperti pada arus jalan B dapat berbelok langsung ke arah jalan A dan pada arus jalan D dapat berbelok langsung ke arah jalan $\mathrm{C}$ hal ini bertujuan untuk melihat apakah dengan menghapus peraturan tersebut akan lebih optimal dibandingkan dengan skema real pada persimpangan sebelumnya.

Keterangan :
$\mathrm{A}=$ Ruas jalan 17 Agustus

$\mathrm{B}=$ Ruas jalan Babe Palar (Timur)

$\mathrm{C}=$ Ruas jalan Maengket

$\mathrm{D}=$ Ruas jalan Babe Palar (Barat)

Dari skema gambar Persimpangan jalan Babe Palar pada Gambar 13 tersebut selanjutnya dibuat arus-arus yang kompatibel atau arus yang dapat berjalan secara bersamaan dan arus Tidak Kompatibel yakni sebaliknya.

Tabel 7. Arus-arus yang Kompatibel dan Tidak Kompatibel

\begin{tabular}{|c|c|c|}
\hline Arus & Kompatibel & $\begin{array}{c}\text { Tidak } \\
\text { Kompatibel }\end{array}$ \\
\hline$a$ & $b, c, d, e, f, g, h, i, j, k, l$ & - \\
\hline$b$ & $a, c, d, g, j, l$ & $e, f, h, k$ \\
\hline$c$ & $a, b, d, e, g, j$ & $e, f, h, i, k, l$ \\
\hline$d$ & $a, b, c, e, f, g, h, i, j, k, l$ & - \\
\hline$e$ & $a, c, d, f, g, j, k$ & $b, h, i, l$ \\
\hline$f$ & $a, d, e, g,, h, j, l$ & $b, c, i, k$ \\
\hline$g$ & $a, b, c, d, e, f, h, i, j, k, l$ & - \\
\hline$h$ & $a, b, d, f, g, i, j$ & $c, e, k, l$ \\
\hline$i$ & $a, d, g, h, j, k$ & $b, c, e, f, l$ \\
\hline$j$ & $a, b, c, d, e, f, g, h, i, k, l$ & - \\
\hline$k$ & $a, d, e, g, i, j, l$ & $b, c, f, h$ \\
\hline$l$ & $a, b, d, f, g, j, k$ & $c, e, h, i$ \\
\hline
\end{tabular}

Setelah itu pada arus kompatibel di Persimpangan yang telah dibuat pada Tabel 7 disalin ke dalam bentuk graf sebagai berikut :

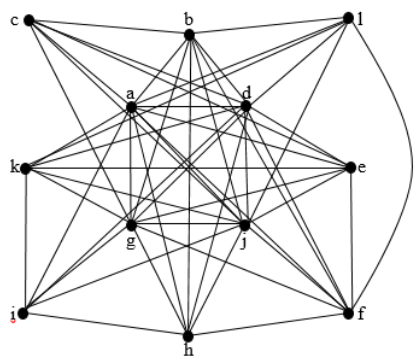

Gambar 14. Graf Arus Kompatibel

kemudian graf Kompatibel diatas disederhanakan dengan cara menghilang titik $a, d, g, j$ karena ke empat arus tersebut Kompatibel atau dapat berjalan langsung tanpa mengikuti nyala lampu lalu lintas sehingga pada Gambar 14 berubah menjadi sebagai berikut :

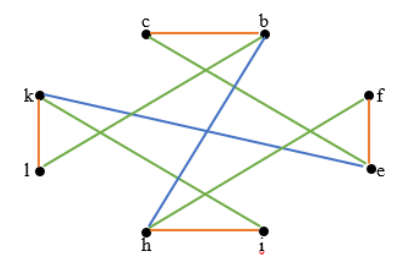

Gambar 15. Graf Kompatibel yang disederhanakan

Ket :

- Untuk sisi yang berwarna oranye adalah pasangan arus yang berjalan secara bersamaan

- Sisi yang berwarna biru adalah pasangan arus yang berlawanan arah

- Sisi yang berwarna hijau adalah pasangan arus yang menuju ke arah yang sama 
Selanjutnya dari graf kompatibel yang telah disederhanakan diubah ke dalam bentuk graf ganda berarah berbobot dengan asumsi yang telah ditentukan sehingga menjadi seperti pada gambar berikut :

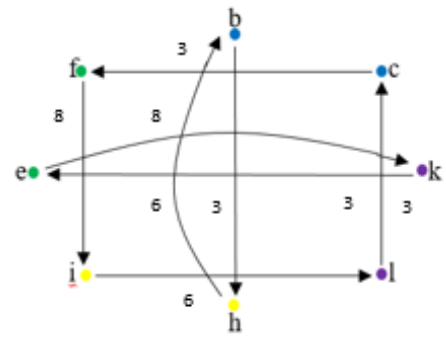

Gambar 16. Graf Ganda Berarah Berbobot

Karena pada jalan Babe Palar Barat dan jalan Babe Palar Timur memiliki bobot yang sama maka jumlah fase pada Lampu Lalu Lintas yang akan dicari adalah sebanyak 3 fase.

Tabel 8. Volume Lalu Lintas di Jalan 17 Agustus

\begin{tabular}{|c|c|c|c|c|c|c|c|c|}
\hline \multirow{2}{*}{ Waktu } & \multicolumn{2}{|c|}{$\begin{array}{c}\text { (LV) } \\
\text { Emp = 1,0 }\end{array}$} & \multicolumn{2}{c|}{$\begin{array}{c}\text { (HV) } \\
\text { Emp = 1,3 }\end{array}$} & \multicolumn{2}{c|}{$\begin{array}{c}\text { (MC) } \\
\text { Emp = 0,2 }\end{array}$} & \multicolumn{2}{c|}{ Jumlah } \\
\cline { 2 - 9 } & kend & smp & kend & smp & kend & smp & Kend/jam & Smp/jam \\
\hline a & b & c & d & e & f & g & h=b+d+f & i=c+e+g \\
\hline $\begin{array}{c}07.30 \\
- \\
08.30\end{array}$ & 565 & 565 & 1 & 1,3 & 627 & 125,4 & 1193 & 691,7 \\
\hline $\begin{array}{c}12.00 \\
- \\
13.00\end{array}$ & 210 & 210 & 2 & 2,6 & 331 & 66,2 & 543 & 278,8 \\
\hline $\begin{array}{c}16.30 \\
- \\
17.30\end{array}$ & 303 & 303 & 1 & 1,3 & 494 & 98,8 & 798 & 403,1 \\
\hline
\end{tabular}

Tabel 9. Volume Lalu Lintas di Jalan Babe Palar Timur

\begin{tabular}{|c|c|c|c|c|c|c|c|c|}
\hline \multirow{2}{*}{ Waktu } & \multicolumn{2}{|c|}{$\begin{array}{c}\text { (LV) } \\
\text { Emp = 1,0 }\end{array}$} & \multicolumn{2}{c|}{$\begin{array}{c}\text { (HV) } \\
\text { Emp = 1,3 }\end{array}$} & \multicolumn{2}{c|}{$\begin{array}{c}\text { (MC) } \\
\text { Emp = 0,2 }\end{array}$} & \multicolumn{2}{c|}{ Jumlah } \\
\cline { 2 - 9 } & kend & smp & kend & smp & kend & smp & Kend/jam & Smp/jam \\
\hline a & b & c & d & e & f & g & h=b+d+f & i=c+e+g \\
\hline $\begin{array}{c}\text { 07.30 } \\
- \\
08.30\end{array}$ & 633 & 633 & 1 & 1,3 & 930 & 186 & 1564 & 820,3 \\
\hline $\begin{array}{c}12.00 \\
- \\
13.00\end{array}$ & 247 & 247 & 0 & 0 & 382 & 76,4 & 629 & 323,4 \\
\hline $\begin{array}{c}16.30 \\
- \\
17.30\end{array}$ & 370 & 370 & 1 & 1,3 & 493 & 98,6 & 864 & 469,9 \\
\hline
\end{tabular}

Tabel 1o. Volume Lalu Lintas di Jalan Maengket

\begin{tabular}{|c|c|c|c|c|c|c|c|c|}
\hline \multirow{2}{*}{ Waktu } & \multicolumn{2}{|c|}{$\begin{array}{c}\text { (LV) } \\
\text { Emp =1,0 }\end{array}$} & \multicolumn{2}{c|}{$\begin{array}{c}\text { (HV) } \\
\text { Emp = 1,3 }\end{array}$} & \multicolumn{2}{c|}{$\begin{array}{c}\text { (MC) } \\
\text { Emp = 0,2 }\end{array}$} & \multicolumn{2}{c|}{ Jumlah } \\
\cline { 2 - 9 } & Kend & smp & kend & smp & kend & smp & Kend/jam & Smp/jam \\
\hline a & B & c & d & e & F & g & h=b+d+f & i=c+e+g \\
\hline $\begin{array}{c}\text { 07.30 } \\
\text { 08.30 }\end{array}$ & 384 & 384 & 2 & 2,6 & 499 & 99,8 & 885 & 486,4 \\
\hline $\begin{array}{c}12.00 \\
- \\
13.00\end{array}$ & 159 & 159 & 1 & 1,3 & 205 & 41 & 365 & 201,3 \\
\hline $\begin{array}{c}16.30 \\
- \\
17.30\end{array}$ & 273 & 273 & 0 & 0 & 450 & 90 & 723 & 363 \\
\hline
\end{tabular}

Tabel 11. Volume Lalu Lintas di Jalan Babe palar barat

\begin{tabular}{|c|c|c|c|c|c|c|c|c|}
\hline \multirow{2}{*}{ Waktu } & \multicolumn{2}{|c|}{$\begin{array}{c}\text { (LV) } \\
\text { Emp = 1,0 }\end{array}$} & \multicolumn{2}{c|}{$\begin{array}{c}\text { (HV) } \\
\text { Emp = 1,3 }\end{array}$} & \multicolumn{2}{c|}{$\begin{array}{c}\text { (MC) } \\
\text { Emp = 0,2 }\end{array}$} & \multicolumn{2}{c|}{ Jumlah } \\
\cline { 2 - 9 } & kend & smp & kend & smp & kend & smp & Kend/jam & Smp/jam \\
\hline a & b & c & d & e & f & g & h=b+d+f & i=c+e+g \\
\hline $\begin{array}{c}\text { 07.30 } \\
\text { 08.30 }\end{array}$ & 330 & 330 & 2 & 2,6 & 529 & 105,8 & 861 & 438,4 \\
\hline $\begin{array}{c}12.00 \\
- \\
13.00\end{array}$ & 153 & 153 & 2 & 2,6 & 220 & 44 & 375 & 199,6 \\
\hline $\begin{array}{c}16.30 \\
- \\
17.30\end{array}$ & 278 & 278 & 1 & 1,3 & 340 & 68 & 619 & 347,3 \\
\hline
\end{tabular}

Keterangan :

$\begin{array}{ll}\text { LV }(\text { Light Vehicle }) & =\text { Kendaraan Ringan } \\ \text { HV }(\text { HeavyVehicle }) & =\text { Kendaraan Berat } \\ \text { MC }(\text { Motorcycle }) & =\text { Sepeda Motor }\end{array}$

\subsubsection{Pengoptimalan dengan metode Webster}

a. Menghitung Siklus Optimum :

1. Waktu Hilang $(\mathrm{R})=5$ detik

2. Arus Jenuh untuk setiap Persimpangan :
a. Pada jalan 17. Agustus $6 m \times 525=3150$
b. Pada jalan Babe Palar (Timur) $4 m=1975$
c. Pada jalan Maengket $4,5 m=2175$
d. Pada jalan Babe Palar (Barat) $4 m=1975$

3. Menentukan tingkat Arus Lalu lintas (y) :

$$
\begin{array}{ll}
\text { a. } & y_{A}=\frac{692}{3150}=0,2197 \\
\text { b. } & y_{B}=\frac{486}{1975}=0,2461 \\
\text { c. } \quad y_{C}=\frac{821}{2175}=0,3775 \\
\text { d. } \quad y_{D}=\frac{438}{1975}=0,2217 \\
Y & =\sum y_{i} \\
& =0,2197+0,2461+0,3775 \\
& =0,8433
\end{array}
$$

4. Untuk waktu hilang total per siklus $(L)$

$$
\begin{aligned}
L & =2 n+R \\
& =2(3)+5=11
\end{aligned}
$$

Maka : 


$$
\begin{aligned}
C_{0} & =\frac{1,5 \times L+5}{1-Y} \\
& =\frac{1,5 \times 11+5}{1-0,8433} \\
& =\frac{21,5}{0,1567} \\
& =137,21 \approx 137 \text { detik }
\end{aligned}
$$

b. Dan untuk Waktu Hijau Maksimum, yaitu :

$$
\begin{aligned}
& C_{0}-L \\
& =137-11 \\
& =126 \text { detik }
\end{aligned}
$$

c. Untuk waktu hijau efektif setiap fase :

$$
\text { a. } \begin{aligned}
g_{3} & =\frac{0,2197 \times 126}{0,8433} \\
& =\frac{27,6822}{0,8433} \\
& =32,83 \approx 33 \text { detik } \\
\text { b. } \quad g_{2} & =\frac{0,2461 \times 126}{0,8433} \\
& =\frac{31,0086}{0,8433} \\
& =36,77 \approx 37 \text { detik } \\
\text { c. } \quad g_{1} & =\frac{0,3775 \times 126}{0,8433} \\
& =\frac{47,565}{0,8433} \\
& =56,41 \approx 56 \text { detik }
\end{aligned}
$$

d. Untuk waktu merah setiap fase :

$$
\text { a. } \begin{aligned}
\text { Fase } 1 & =C_{0}-\text { waktu hijau - waktu kuning } \\
& =137-33-5 \\
& =99 \text { detik } \\
\text { b. Fase } 2= & C_{0}-\text { waktu hijau - waktu kuning } \\
& =137-37-5 \\
& =95 \text { detik } \\
\text { c. } \quad \text { Fase } 3= & C_{0}-\text { waktu hijau - waktu kuning } \\
& =137-56-5 \\
& =76 \text { detik }
\end{aligned}
$$

\subsubsection{Hasil Pengolahan}

Berdasarkan hasil dari pengolahan dengan menggunakan metode webster maka data baru yang diperoleh adalah sebagai berikut :

Tabel 12. Data Baru Waktu Lampu Lalu Lintas

\begin{tabular}{|l|c|c|c|}
\hline \multicolumn{1}{|c|}{ Ruas Jalan } & $\begin{array}{c}\text { Merah } \\
\text { (detik) }\end{array}$ & $\begin{array}{c}\text { Kuning } \\
\text { (detik) }\end{array}$ & $\begin{array}{c}\text { Hijau } \\
\text { (detik) }\end{array}$ \\
\hline Jl 17 Agustus & 99 & 5 & 33 \\
\hline $\begin{array}{l}\text { Jl Babe Palar } \\
\text { (Timur) }\end{array}$ & 95 & 5 & 37 \\
\hline Jl Maengket & 76 & 5 & 56 \\
\hline $\begin{array}{l}\text { Jl Babe Palar } \\
\text { (Barat) }\end{array}$ & 95 & 5 & 37 \\
\hline
\end{tabular}

\section{Penutup}

\subsection{Kesimpulan}

Kesimpulan yang dapat diambil adalah berdasarkan dari hasil penghitungan dengan menggunakan metode webster dikatakan efektif yakni penghitungan tersebut menghasilkan waktu siklus optimum persimpangan sebesar 137 detik dan lebih optimal dibandingkan data sekunder yang mempunyai waktu siklus optimum sebesar 171 detik.

Hasil perhitungan dengan menggunakan metode webster pada ruas jalan Maengket yang memiliki tingkat volume lalu lintas yang tinggi terjadi pengurangan pada waktu nyala lampu merah yakni yang sebelumnya 103 detik berkurang menjadi 76 detik dan terjadi penambahan pada nyala lampu hijau yakni yang sebelumnya 22 detik bertambah menjadi 56 detik.

Dan untuk pengaturan arus dengan asumsi yang telah dibuat yakni dapat langsung berbelok ke arah kanan diketahui lebih optimal dan konflik yang terjadi lebih kecil dibandingkan dengan pengaturan real dari persimpangan.

\subsection{Saran}

Untuk penelitian selanjutnya disarankan agar menambahkan beberapa variabel pengguna jalan lainnnya.

\section{REFERENSI}

[1] Anisa, D. 2015. Penerapan Metode Webster Untuk Lampu Lalu Lintas di Bogot [Skripsi]. Fakultas Matematika dan Ilmu Pengetahuan Alam Institut Pertanian Bogor, Bogor.

[2] Cahyani, U. 2018. Optimasi Pengaturan Lampu Lalu Lintas Kota Medan Menggunakan Graf dan Metode Webster [Skripsi]. Fakultas Matematika dan Ilmu Pengetahuan Alam Universitas Sumatera Utara, Medan.

[3] Diana. E. Lus., S. Wahyuni dan S. Endang. 2016. Pengaturan Lampu Lalu Lintas di Persimpangan Jalan Ahmad Yani Giant dengan Aplikasi Pewarnaan Teori Graf. Journal of Mathematics, Science and Technology 1 : $69-85$.

[4] Departemen Pekerjaan Umum. 1997. Manual Kapasitas Jalan Indonesia. Direktorat Jendral Bina Marga. Jakarta.

[5] Hosseini, S. M. dan Orooji. H. 2009. Phasing Light at a Road Junction. Aplied Matehematical Science. 30 : 1487 - 1492.

[6] Khisty, C. J. , dan B. K. Lall, 2003. Dasar-dasar Rekayasa Transportasi Jilid 1. Edisi ketiga. Erlangga, Jakarta.

[7] Munir, R. 2005. Matematika Diskrit. Informatika, Bandung.

[8] Munir, R. 2010. Matematika Diskrit. Edisi ke-3. Informatika, Bandung.

[9] Munir, R. 2012. Matematika Diskrit. Informatika, Bandung.

[10] Miftahurrahmah. 2016. Aplikasi Teori Graf dalam Pengaturan Lampu Lalu Lintas [Skripsi]. Fakultas Sains dan Teknologi Universitas Islam Negeri Alauddin, Makassar. 
[11] Meiliana, C. Heni., dan D. Maryono. 2014. Aplikasi Pewarnaan Graf Untuk Optimalisasi Pengaturan Traffic Light di Sukoharjo. JIPTEK 1: 25-34.

[12] Rosen, K. H. 2012. Discrete Mathematics and its Applications. $7^{\text {th }}$ Edition. McGraw-Hill, New York.

[13] Sudirman Y. Krisna, Hendra dan Maseleno Andino. 2005. Simulasi Numerik Untuk Otomasi Sistem Pengaturan Lampu Lalu Lintas Berdasarkan Volume Kepadatan Lalu Lintas Dengan Menggunakan PLC. Prosiding Seminar Nasional Manajemen Teknologi I, Yogyakarta, 25-26 Februari 2005. Hlm 1-9.

[14] Tamin, Ofyar. Z. 200o. Perencanaan dan Pemodelan Transportasi. Edisi Kedua. ITB, Bandung.

[15] Webster. F. V. 1958. Traffic Signal Setting Road Research Technique Paper No. 39, Road Research Laboratory, London.

[16] Wirawan T. Pandu. 2008. Pemodelan Sistem Lalu Lintas dengan Graf Ganda Berarah Berbobot. Makalah Jurusan Teknik Informatika. Institut Teknologi Bandung, Bandung.

[17] http://www.manadokota.go.id [ 20 Oktober 2018].

Indah Poernamasari (Indahpoernamasari46@gmail.com)

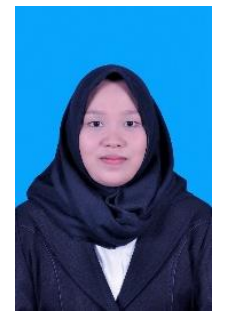

Lahir di Manado, Sulawesi Utara pada tanggal 21 Juli 1997. Menempuh pendidikan tinggi di Jurusan Matematika FMIPA, Universitas Sam Ratulangi Manado. Tahun 2018 adalah tahun terakhir ia menempuh studi. Makalah ini merupakan hasil penelitian skripsinya yang dipublikasikan.

Rinancy Tumilaar (rinancytumilaar@gmail.com)

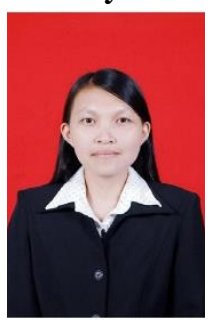

Pada tahun 2010 memperoleh gelar sarjana pada program studi Matematika, Universitas Sam Ratulangi Manado, gelar Magister Sains diperoleh dari Institut Pertanian Bogor pada tahun 2014. Dan menjadi dosen dijurusan Matematika FMIPA Universitas Sam Ratulangi Manado Pada tahun 2014 sampai sekarang.

Chriestie E.J.C. Montolalu (Chriestelly@yahoo.com)

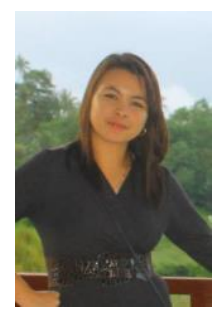
Lahir pada tanggal 10 Desember 1985. Pada tahun 2007 mendapatkan gelar Sarjana Sains (S.Si) yang diperoleh dari Universitas Sam Ratulangi Manado. Gelar Master Of Science (M.Sc) diperoleh dari Universitas Of Queensland Australia pada tahun 2015. Ia bekerja di UNSRAT di Program Studi Matematika sebagai pengajar akademik tetap UNSRAT. 